\title{
Urban impacts on air temperature and precipitation over The Netherlands
}

\author{
Vahid Rahimpour Golroudbary*, Yijian Zeng, Chris M. Mannaerts, \\ Zhongbo (Bob) Su
}

Faculty of Geo-Information Science and Earth Observation (ITC), Department of Water Resources, University of Twente, Enschede, The Netherlands

\begin{abstract}
The detection of changes in the weather of urban areas is an important issue for understanding the impact of weather on human lives. Five years of basic weather observations (2011-2015) from automatic and amateur networks across The Netherlands were used to investigate the urban effects on meteorological parameters with a focus on temperature (e.g. urban heat island $[\mathrm{UHI}])$ and precipitation. Representative stations were selected based on metadata and a set of criteria for data quality control. An hourly analysis indicates that UHIs are a nocturnal phenomenon in The Netherlands and are more prominent after sunset, when they exceed $2^{\circ} \mathrm{C}$. A seasonal analysis shows that UHIs occur in all seasons during the year, with the most significant UHI occurring in the summer. Furthermore, the differences in the precipitation of urban and rural areas were shown to be greatest after sunrise during the day. The maximum hourly UHI and hourly precipitation distributions were analyzed using a generalized extreme value model. The occurrences of maximum precipitation are likely to be more frequent at urban stations than at the nearby rural stations. Additionally, the distinct seasonal cycle of precipitation that is dependent on the UHI demonstrates that the maximum UHI and precipitation occurred in the summer. Our results indicate that the UHI and precipitation enhancements in Dutch urban residential areas, as obtained from the data of weather amateurs, are in agreement with the results presented in the literature, and that $7 \%$ more precipitation occurs in cities than in rural areas.
\end{abstract}

KEY WORDS: Urban impacts - Amateur weather stations - Meteorological parameters · Temperature $\cdot$ Precipitation $\cdot$ Urban heat island $\cdot$ Population density

\section{INTRODUCTION}

Urbanization is increasing dramatically and, consequently, the surface characteristics and local climates of urban areas will be considerably affected (Han et al. 2014). Urbanization modifies the radiation, thermal and dynamic characteristics of the underlying surface, and makes the land cover in urban areas quite different from that of the surrounding areas. These differences result in a horizontal gradient of energy and moisture in the surrounding environment, impacting the boundary layer characteristics as well as the heat and water exchanges between the

${ }^{*}$ Corresponding author:

v.rahimpourgolroudbary@utwente.nl land surface and the atmosphere, which may lead to alterations of temperature and precipitation patterns (Sailor 2011, Mills 2014).

The physical properties of city buildings are known to modify the energy budget and the exchanges of fluxes between the land surface and atmosphere (e.g. heat, water, and momentum between the land surface and overlying atmosphere), which cause alterations of the atmospheric composition and meteorology over urban areas (Peterson 2003, Kaufmann et al. 2007, Pall et al. 2007, Trusilova et al. 2008, Zhang et al. 2009, Lin et al. 2011, Stone et al. 2012).

Studies over the past decades have focused on the

() The authors 2018. Open Access under Creative Commons by Attribution Licence. Use, distribution and reproduction are unrestricted. Authors and original publication must be credited. 
urban surface energy balance and urban heat island (UHI). UHIs can be generated by changes in the climate system due to land-use changes associated with urbanization (Oke 1982). These changes could be induced by well-known factors, such as urban geometry, air pollution, anthropogenic heat, or impervious surfaces (Ryu \& Baik 2012). Building densities and reduced vegetation inhibit urban albedo and enhance the heat stored in urban areas (Erell et al. 2011).

The UHI effects on mesoscale circulation can be observed in convective precipitation (Shepherd 2005). In the past decade, numerous studies have reported that urban morphological parameters can considerably influence precipitation variability (Ikebuchi et al. 2007, Shem \& Shepherd 2009, Niyogi et al. 2011, Hu et al. 2012, Willems et al. 2012, Chen et al. 2015). The possible mechanism leading to the discrepancy in the precipitation of urban areas and that of their surrounding areas has been discussed by Shepherd (2005) as being (1) an increased convergence due to extended surface roughness, (2) destabilization caused by UHI perturbations of the planetary boundary layer, or (3) enhanced aerosols in an urban environment for cloud condensation nuclei sources.

The Netherlands can be defined as an urbanized area (comprising mid-sized cities with $<10 \mathrm{~km}$ radii) inside the Meuse and Rhine river delta, with many sections situated below sea level (Steeneveld et al. 2011). Despite the vast number of international reports on urban climates, particular outcomes cannot be clearly extrapolated to the Dutch circumstances. The existing studies (e.g. focusing on the UHI and its effects on rainfall intensities at the local level, especially in the coming years) are not reliable enough to serve as indicators of UHI and extreme rainfall events for many of the cities in The Netherlands (Schlünzen et al. 2010, Van Hove et al. 2011). The variations of climatic conditions, air quality, urban landscapes and geometries, and building types and components render such extrapolations challenging. It becomes imperative to understand the interactions between Dutch urbanization and meteorological observations, especially those of extreme weather conditions that could threaten citizens and vital infrastructure (Rovers et al. 2014). Very few studies have delineated the Dutch urbanization effects on the relationship between temperature and precipitation (e.g. Brandsma et al. 2003, Haines et al. 2006).

Approximately $90 \%$ of the Dutch population in 2014 was concentrated in urban regions, with at least 90000 inhabitants (Un 2015). The urbanization and population average growth rates $(0.77 \%$ and $1.05 \%$, respectively) between 2010 and 2015 indicate a fairly rapid urbanization in The Netherlands (Un 2015). Although there has been a continuous urbanization in The Netherlands (Hazeu et al. 2011, Daniels et al. 2015), long-term meteorological observations are scarce for Dutch cities (for more details, see Van Hove et al. 2011). The study presented here attempts to investigate the temperature and precipitation variations using citizens' personal amateur weather stations (PWS) to understand the urban environments of a number of Dutch cities (Jiang et al. 2016). The lack of long-term urban meteorological data in Dutch cities motivates the use of observations from PWS. Observations from PWS in The Netherlands have previously been used by Steeneveld et al. (2011) and Wolters \& Brandsma (2012). These studies investigated UHI effects on human comfort and factors influencing UHIs, whereas the present study concentrates more on urban-rural temperature and precipitation differences and on the urbanization effects on the relationship of temperature and precipitation. In contrast to the aforementioned studies, the urbanization effects in the present study mainly focus on the hourly UHI and precipitation values of a $5 \mathrm{yr}$ period (2011-2015). The hourly temperature and precipitation data at local time (LT) were obtained by averaging available sub-hourly values for temperature and accumulated precipitation amount for each hour, respectively. The most populated areas in the western and northern regions of The Netherlands (approximately $60 \mathrm{~km}$ from the North Sea) were considered in this study (see Rahimpour Golroudbary et al. 2017). A dedicated process based on the city size and data availability (section 2) was used to select the stations.

This study quantifies the gradients of meteorological variables between the urban and surrounding rural areas. The records from PWS were used, and the data were investigated separately for day and night. The generalized extreme value (GEV) approach and bootstrap method were used to determine the distributions of the maximum hourly UHI and precipitation in the cities for 2011-2015.

\section{DATA AND METHODS}

A large number of automatic weather stations (AWS) that are in accordance with World Meteorological Organization (WMO) standards exist in The Netherlands (every $1000 \mathrm{~km}^{2}$ ) and have been installed in very open areas without any obstacles 
around the temperature and precipitation instruments (Wolters \& Brandsma 2012). Due to their nature, AWS are mainly located in rural areas. In the absence of WMO stations in Dutch cities, PWS were studied for their use as urban stations. The rural stations (AWS) were selected based on their distances to the selected PWS. The investigated PWS have their data published on 2 weather websites (www.wunderground.com and www.hetweeractueel.nl). The present study considered all available PWS in The Netherlands to select appropriate stations within Dutch cities. The lack of archived data in most PWS inside Dutch cities limits the study period to 2011-2015. The 11 PWS stations were selected based on their locations, instrument types and accuracy, the available record lengths and the data quality (see section 2.2).

\subsection{Data quality control}

Although the quality of the AWS data is controlled by the Koninklijk Nederlands Meteorologisch Instituut (KNMI), there is a lack of professional quality control (QC) for the PWS archived data. The PWS require data $\mathrm{QC}$ to obtain reliable observations (Fig. 1).

The PWS QC includes instrument issues and setup issues (adverse effects of local installations). The instrument assessment was limited to the defined uncertainties of PWS manufacturers because an intercomparison of all PWS is virtually impossible (Steeneveld et al. 2011).

The typical uncertainties for the deduced parameters from PWS are listed in Table 1 (and are similar to each other with only small differences). In contrast, the AWS accuracies reported by KNMI are $0.1^{\circ} \mathrm{C}, 3 \%$ and $0.5 \mathrm{~m} \mathrm{~s}^{-1}$ for temperature, humidity and wind speed, respectively (Van Hove et al. 2015).

The selected PWS (most of them are Vantage Pro series) are similar to those amateur stations used by previous studies (e.g. McLaren et al. 2005, Wiacek et al. 2007, Steeneveld et al. 2011). The Wolters \& Brandsma (2012) approach (which is based on established ideas about in situ urban meteorological observations, as summarized in Oke 2004) was applied to select representative stations from the available PWS in cities. The selection approach considered a number of criteria regarding a station's detailed metadata and sufficient information concerning the observational circumstances (see Fig. 1). In this respect, the selected PWS for this study have shielded temperature sensors and active ventilation to avoid direct sunlight. In addition, the distance to

Table 1. Measurement accuracy defined by manufacturers for each type of station

\begin{tabular}{|lccccc|}
\hline Station type & $\begin{array}{c}\text { Temperature } \\
\left({ }^{\circ} \mathrm{C}\right)\end{array}$ & $\begin{array}{c}\text { Humidity } \\
(\%)\end{array}$ & $\begin{array}{c}\text { Wind speed } \\
\left(\mathrm{m} \mathrm{s}^{-1}\right)\end{array}$ & $\begin{array}{c}\text { Precipitation } \\
(\mathrm{mm})\end{array}$ & $\begin{array}{c}\text { Pressure } \\
(\mathrm{hPa})\end{array}$ \\
\hline Alecto WS-4000 (I) & 0.1 & 1 & - & 0.1 & 0.1 \\
Davis Vantage Pro 2 or 2+ (II) & 0.5 & 3 & 1 & 1 & 1 \\
Davis Vantage VUE (III) & 0.5 & 3 & 3 & 1 & 1 \\
Oregon Scientific WMRS200 (IV) & 3 & 7 & 0.9 & 0.2 & 0.1 \\
Oregon Scientific WMR928n (V) & 0.5 & 3 & 0.9 & -1 \\
CRESTA WXR 815 (VI) & 1 & 5 & 0.5 & 5 \\
TFA Nexus Pro (VII) & 1 & 5 & & \\
\hline
\end{tabular}


the surface of the temperature sensor (height of sensor) is set to be $>1.5 \mathrm{~m}$ for the selected sheltered stations (without radiation exposure; Oke 2004). For a rural background climate, the meteorological observations were explored using the AWS. Other external forces have been proven to have potential effects on local climate observations (such as coastal breezes, regional circulation, annual cycles in the observation, open water influences, and soil types) (Van Hove et al. 2015, 2011). To separate these forcing effects from the investigations of urban impacts on temperature and precipitation, the PWS and nearest AWS were paired off by their similar influences from the aforementioned external forces. Although this approach cannot totally remove all external forces, it helps diminish their impacts on the analysis of the overall features of the temperature and precipitation discrepancies between the urban and rural, which is focused on in this study. Consequently, this study assumes that the paired urban and rural areas are affected by approximately the same external influences.

To achieve more reliable results with data analysis, the QC of long-term hourly data from PWS is required. The basic quality requirements follow those of their respective WMO guidelines, as followed by Klein Tank (2007) for the European Climate Assessment \& Dataset (ECA\&D) meteorological measurements (see more details in Table 2 and the WMO 2007 guidelines). The last row in Table 2 shows the condition for detecting constant values (the repetitive same values) that might be recorded due to digitization error. In practice, these constant values, the improbable zero measurements, and the unusually low or high values (or physically impossible data) were detected as suspect values at each station. Then, the suspect values at each station were compared with the values of the nearest stations. If the neighbouring stations recorded significantly higher or lower values than the suspect value, those values were flagged within the data series.

\subsection{Selected stations}

Fig. 2 shows the locations of the favourable stations for investigating possible urban climate effects. The appropriate PWS observations are lacking for the urban areas in the east, middle and south of the country during the investigated $5 \mathrm{yr}$ period (e.g. according to the criteria listed in Fig. 1). The selected PWS cover the west of The Netherlands within the range of $<60 \mathrm{~km}$ to the coast, which experienced more increased precipitation than the other parts of the country in the past decades (Buishand et al. 2013, Rahimpour et al. 2016). This part of the country includes the majority of urban areas with dense populations of $>300000$ inhabitants (i.e. The Hague, Delft, and Rotterdam).

Table 3 describes more of the details of the selected stations for further analysis. These stations have similar designs and are classified as urban stations by the Dutch amateur website (www.hetweeractueel. $\mathrm{nl})$. The local climate zone (LCZ) around each PWS (buffer with $0.3 \mathrm{~km}$ radius) is classified as open midrise (OMR) or open low-rise (OLR) following the classification by Stewart \& Oke (2012). These classes define the slight reduction of the visible sky, abundant plant cover and scattered trees over urban areas. OMR consists of buildings of 3-9 stories made of heavy materials and thick walls. Likewise, OLR consists of small buildings of 1-3 stories that are built of wood, tile, brick or stone (Id 2011). Further, the land-use information regarding the degree of urbanity, address density and population density was extracted for approximately $5 \mathrm{~km}$ around each station (Suomi et al. 2012) from the available database of the Dutch national statistics of 2015 (CBS 2015). The population around the stations were further considered to select suitable urban stations for further investigation. For very small population density, the averaged observed UHI was close to zero. The results of the temperature-population density relationship indicate that the applied criteria for station selection based on the metadata considered was effective. The

Table 2. Quality control for the temperature and precipitation parameters (Jarrand 2008)

\begin{tabular}{|lcc|}
\hline Parameter & Precipitation amount (R) & Air temperature $(T)$ \\
\hline Possible range & $0 \leq \mathrm{R} \leq 40 \mathrm{~mm} \mathrm{~min}^{-1}$ and $0 \leq \mathrm{R} \leq 300 \mathrm{~mm} \mathrm{~d}^{-1}$ & $-80 \leq T \leq 60^{\circ} \mathrm{C}$ \\
$\begin{array}{l}\text { Required measurement } \\
\text { uncertainty }\end{array}$ & $0.1 \mathrm{~mm}$ for $\mathrm{R}<5 \mathrm{~mm}$ and $2 \%$ for $\mathrm{R}>5 \mathrm{~mm}$ & $0.1 \mathrm{~K}$ for $-40<T \leq 40{ }^{\circ} \mathrm{C}$ \\
$\begin{array}{l}\text { Possible constant values } \\
\text { quantified based on daily }\end{array}$ & For $10 \mathrm{~d}$ if $\mathrm{R} \geq 1.0 \mathrm{~mm}$ and for $5 \mathrm{~d}$ if $\mathrm{R}>5 \mathrm{~mm}$ & and $0.3 \mathrm{~K}$ for $T>40^{\circ} \mathrm{C}$ or $T \leq-40^{\circ} \mathrm{C}$ \\
For $5 \mathrm{~d}$
\end{tabular}




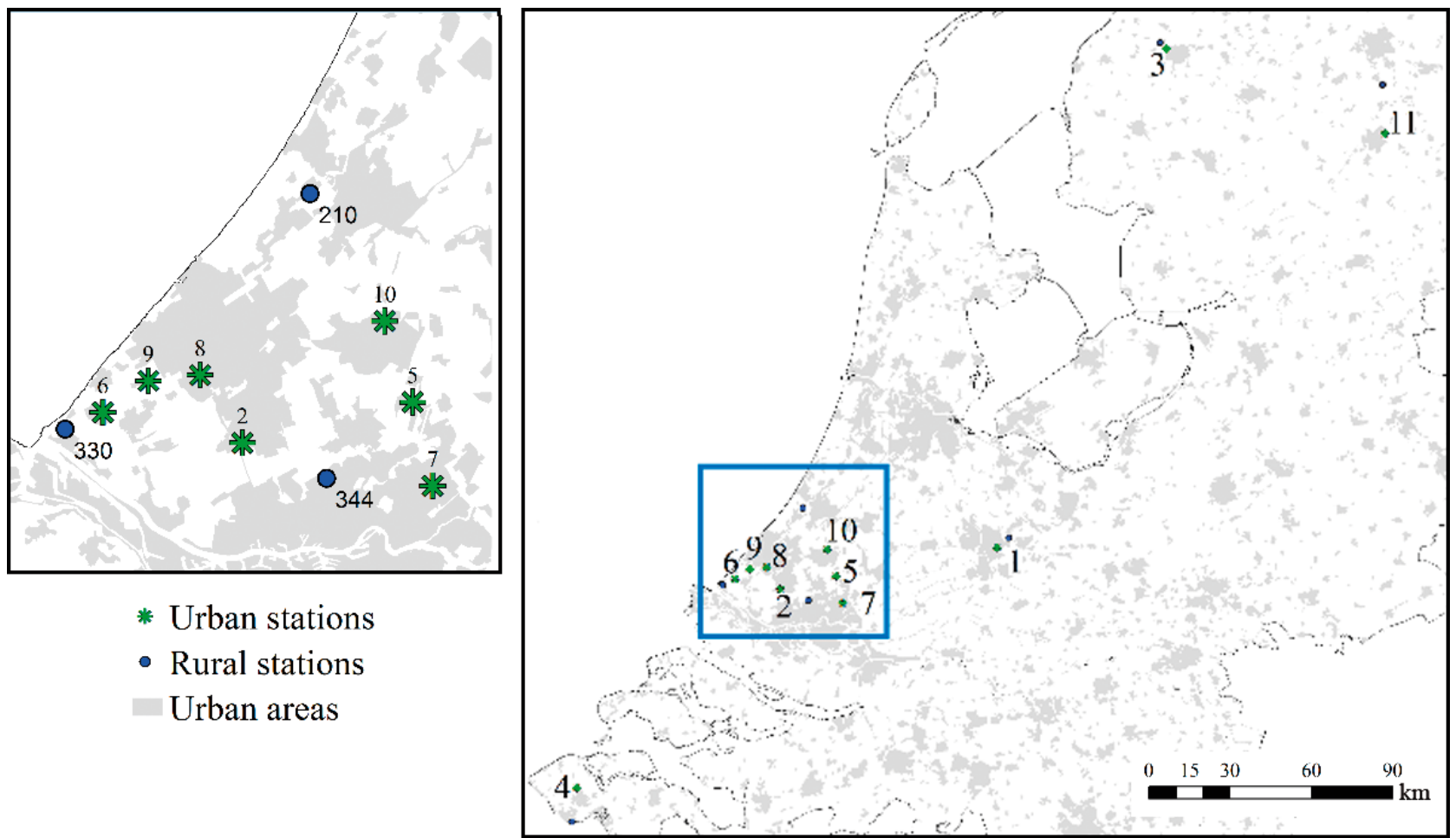

Fig. 2. Urban (PWS) and rural (AWS) stations used in the present study. The urban stations with 1000 addresses per square kilometre are marked with asterisks and their labels correspond to the rows in Table 3. Gray shading indicates urban areas in The Netherlands (EEA 2014)

Table 3. Information of selected urban stations extracted for a $5 \mathrm{~km}$ radius around the station. Row: the numbers correspond to labels in Fig. 2. Type: see details in Table 1; LCZ: local climate zone for $0.3 \mathrm{~km}$ radius around the personal amateur weather stations (PWS) (OMR: open mid-rise, OLR: open low-rise); OAD: address density per $\mathrm{km}^{2}$; STED: urbanity degree (1: very strong urban $\geq 2500$ addresses per $\mathrm{km}^{2} ; 2$ : strong urban 1500-2500 addresses per $\mathrm{km}^{2} ; 3$ : moderate urban 1000-1500 addresses per km²); POP: population; PD: population density per $\mathrm{km}^{2}$; D: distance between urban (PWS) and paired rural (AWS) (km); AWS: corresponding KNMI stations

\begin{tabular}{|c|c|c|c|c|c|c|c|c|c|c|c|c|c|c|}
\hline Row & PWS & Lat & Long & $\begin{array}{l}\text { Elevation } \\
\text { (m) }\end{array}$ & City & Province & Type & $\mathrm{LCZ}$ & OAD & STED & POP & $\mathrm{PD}$ & $\mathrm{D}$ & AWS \\
\hline 1 & IUTRECHT23 & 52.08 & 5.14 & 9 & Utrecht & Utrecht & I & OMR & 3184 & 1 & 321915 & 3415 & 3.5 & 260 \\
\hline 2 & IDELFT1 & 51.98 & 4.34 & -1 & Delft & Zuid-Holland & II & OMR & 3384 & 1 & 99095 & 4340 & 7.5 & 344 \\
\hline 3 & IFRIESLA8 & 53.21 & 5.77 & 0 & Leeuwarden & Friesland & II & OLR & 2285 & 2 & 95950 & 1219 & 2 & 270 \\
\hline 4 & IZEELAND16 & 51.51 & 3.61 & 2 & Middelburg & Zeeland & II & OLR & 1717 & 2 & 47520 & 980 & 6.5 & 310 \\
\hline 6 & IZUIDHOL94 & 52.01 & 4.17 & ('s & $\begin{array}{c}\text { Westland } \\
\text { 's-Gravenzande) }\end{array}$ & Zuid-Holland & II & OLR & 1329 & 3 & 10269 & 1291 & 3.5 & 330 \\
\hline 7 & IZUIDHOL36 & 51.95 & 4.57 & 4 & $\begin{array}{c}\text { Capelle } \\
\text { aan den IJssel }\end{array}$ & Zuid-Holland & II & OLR & 2240 & 2 & 66025 & 4644 & 8.7 & 344 \\
\hline 8 & IZUIDHOL92 & 52.03 & 4.29 & (W & $\begin{array}{c}\text { The Hague } \\
\text { Wateringse Veld) }\end{array}$ & Zuid-Holland & II & OLR & 4720 & 1 & 505855 & 6179 & 12 & 344 \\
\hline 11 & IDRENTHE29 & 53.01 & 6.59 & 9 & Assen & Drenthe & II & OLR & 1436 & 3 & 67205 & 154 & 12.5 & 280 \\
\hline
\end{tabular}


selected PWS are located in urban areas with $>1000$ addresses per square kilometre (see Table 3 ).

\subsection{Data analysis}

This study analyzed the temperature and precipitation variables for rural and urban areas. The hourly observation meteorological parameters were investigated during the night-time (the time interval between sunset and sunrise [LT]) and daytime (the time interval between sunrise and sunset [LT]). More details for sunrise and sunset are available at www.time anddate.com/sun/netherlands. UHIs within urban areas vary spatially based on the properties of the surroundings (Rovers et al. 2014). UHIs were calculated using a PWS air temperature ( $\left.T_{\text {Urban }}\right)$ minus the air temperature of the closest AWS ( $\left.T_{\text {Rural }}\right)$ (Oke 1973, Steeneveld et al. 2011), which is written as follows:

$$
\mathrm{UHI}=T_{\text {Urban }}-T_{\text {Rural }}
$$

The average of the observations during the investigated period may be more appropriate than other indices for use in detecting the physical and temporal behaviour of the measurements (Brandsma \& Wolters 2012). However, sometimes the maximum value is needed to characterize the urban measurements independent of their spatiotemporal variation. These maximum values, regardless of their frequencies of occurrence, may have the strongest impacts on human life. Therefore, the $\mathrm{UHI}_{\text {ave }}$ and $\mathrm{UHI}_{\max }$ (the mean and maximum observed UHI values of each month, respectively) were derived from the hourly values.

However, the extreme precipitation intensities could be influenced by many factors, such as atmospheric dynamic advection processes, atmospheric moisture availability and other process (Berg et al. 2013, Attema et al. 2014, Panthou et al. 2014). The relationship between extreme precipitation and temperature (analogous to the Clausius-Clapeyron relation) plays an important role in precipitation formation (Barbero et al. 2017). The Clausius-Clapeyron relation indicates the maximum capacity of an air mass for holding water vapour, which increases by $6-7 \%$ per degree of temperature increase (Allen \& Ingram 2002). This percentage of water vapour enhancement could decrease or increase due to various factors, such as region, duration, season or temperature range (Lenderink \& van Meijgaard 2008, Berg et al. 2013).

To understand the relationship between temperature and precipitation, we followed the method de- scribed by Lenderink \& van Meijgaard (2008). In this respect, the hourly precipitation values were paired with their corresponding temperatures for all wet hours (precipitation $>0 \mathrm{~mm}$ ) at each station for nights from 2011 to 2015 . To examine the temperature-precipitation relationships of the investigated stations, scaling can be used with either the dewpoint temperature or air temperature as the reference (Lenderink et al. 2011). Although the preference is to use the dew point (e.g. including temperature and humidity), in the present study, only the air temperature observations were used, due to the lack of sufficient dew-point observations at the urban stations.

For each station, the sorted P90th temperature was split into 20 bins between 0 and $20^{\circ} \mathrm{C}$ with intervals of $1^{\circ} \mathrm{C}$. Furthermore, a sensitivity analysis of the bin width shows that a $0.5^{\circ} \mathrm{C}$ bin width does not influence the results. The 90th percentile of the hourly precipitations (P90th) was defined as extreme precipitation (ranked from highest to lowest). The wet time fraction (WTF) was estimated using the ratio of the total number of P90th events to the total number of wet hours for each bin. Then, the precipitation fractional (PF) was used to assess the variations of the intensities of the P90th events. The PF was calculated by the fractional contribution of the P90th to total precipitation in each bin (Mishra et al. 2012). The WTF and PF are defined as follows:

$$
\begin{gathered}
\mathrm{WTF}=\frac{\mathrm{N}_{\mathrm{P} 90 \mathrm{th}} i}{\mathrm{~N}_{P} i} \\
\mathrm{PF}=\frac{\sum_{i=0}^{20} \mathrm{P}^{20} \mathrm{th}_{i}}{\sum_{i=0}^{20} P_{i}}
\end{gathered}
$$

where $P$ is the amount of precipitation, $\mathrm{N}_{\mathrm{P} 90 \mathrm{th}} i$ represents the number of hourly extreme precipitation events above the 90th percentile (P90th) in each bin (i) and $\mathrm{N}_{P} i$ is the number of wet hours in each bin.

Investigating the hourly maximum UHI and precipitation for a long time series can be useful for urban climate studies (Steeneveld et al. 2011). The statistical method to evaluate the intensities and frequencies of the maximum observations can be applied to detect the probability distributions of temperature and precipitation (Data 2009). The extreme distribution of the maximum UHI and precipitation can be explained by the GEV method (Coles 2001, Overeem et al. 2008, Steeneveld et al. 2011). Analysing the data via the GEV method leads to the quantification of the degree of observed extremes and their distributions. The maximum hourly values were fitted to GEV as follows: 


$$
F(x ; \mu, \sigma, \varepsilon)=\left\{\begin{array}{c}
\exp \left(-\left[1+\varepsilon \frac{x-\mu}{\sigma}\right]^{-\frac{1}{\varepsilon}}\right), \quad \& \quad \varepsilon \neq 0 \\
\exp \left(-\exp \left(-\frac{x-\mu}{\sigma}\right)\right), \quad \& \quad \varepsilon=0
\end{array}\right.
$$

where: $\quad\left[x: 1+\varepsilon \frac{x-\mu}{\sigma}>0\right], \quad\left\{\begin{array}{c}\mu \in \mathbb{R} \\ \sigma>0 \\ \varepsilon \in \mathbb{R}\end{array}\right.$

where $x$ is the maximum hourly UHI (or precipitation) and $F(x)$ is the cumulative distribution. The distribution maximum is defined by the parameter location $(\mu)$, and the spread of the distribution is defined by the scale parameter $(\sigma>0)$. The shape parameter $\varepsilon$ defines the extreme value distribution types. The maximum likelihood (Jenkinson 1955) was used to estimate the distribution parameters. The fitting distribution approximations are generally accurate due to the primary statistical theory of the maximum likelihood approach (Data 2009). The goodness-of-fit for the GEV estimations and their uncertainties were tested by calculating their confidence intervals and standard errors. The parametric bootstrap method was applied to obtain the confidence intervals. A large enough replicate sample size of $10^{4}$ was chosen to run the parametric bootstrap method (Pattengale et al. 2009).

\section{RESULTS}

\subsection{UHI intensities}

The variations of UHI, as derived from the nearest AWS, were investigated between 2011 and 2015 (Fig. 3) by considering the the diurnal course of the average UHI. Fig. 3 shows the variations of the average hourly UHI for $24 \mathrm{~h}$ during the investigated $5 \mathrm{yr}$ period. The UHI depicts a sinusoidal shape between 0 and $24 \mathrm{~h}$ (LT), with its greatest values exceeding $2^{\circ} \mathrm{C}$ at $18 \mathrm{~h}(\mathrm{LT})$.

A distinct diurnal course of UHI at each station shows stronger and weaker values for UHI at nighttime and in the morning, respectively. The average UHI approaches zero degrees close to sunrise (between 05:00 and 06:00 h LT) and reaches the largest negative values at about 08:00 $\mathrm{h}$ LT. In the morning and afternoon, the average UHI gradually increases and reaches a maximum at about 18:00 h LT. A stronger UHI in the night-time hours was also found in previous studies (Hamdi \& Schayes 2008, Wolters \& Brandsma 2012). These studies suggested that the UHI disappearing after sunrise in the morning is due

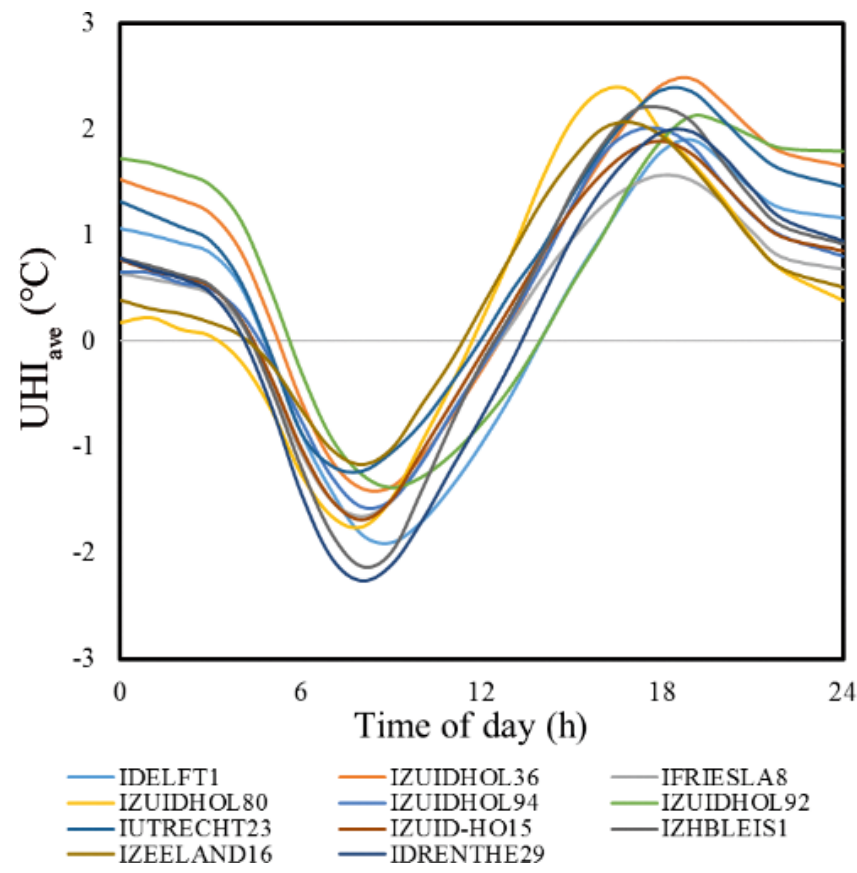

Fig. 3. Hourly variation of mean observed urban heat island values from 2011 to 2015. The UHI at night-time decreases near sunrise

to the effective heat storage, shadowing and low solar radiation, which make urban areas warm up slower than rural areas.

The UHI was detected in all seasons for all stations, and there was a seasonal influence on the magnitude of observed UHI. Fig. 4 shows the average hourly UHI at night for the investigated PWS within the cities for the spring (March-May), summer (June-August), autumn (September-November) and winter (December-February). The magnitudes of the UHI averaged over all cities were -0.08 to $0.63^{\circ} \mathrm{C}$ for the winter and 0.26 to $1.30^{\circ} \mathrm{C}$ for the summer. Likewise, those of the spring were 0.36 to $1^{\circ} \mathrm{C}$, and those in the autumn were -0.01 to $0.81^{\circ} \mathrm{C}$. The UHI could be observed on some days in the winter, although on average, the UHI were minimal during the winter months. The UHI intensity and its statistical distribution most likely depend on other investigated weather parameters as well as the characteristics of the city and countryside. In The Netherlands, cold night or warm nights generally occur with clear sky or fair weather, respectively. The UHI development in both aforementioned situations occurs more during calm conditions with little wind speed, and is also dependent on sea level pressure and humidity (Steeneveld et al. 2010, Wolters \& Brandsma 2012). 

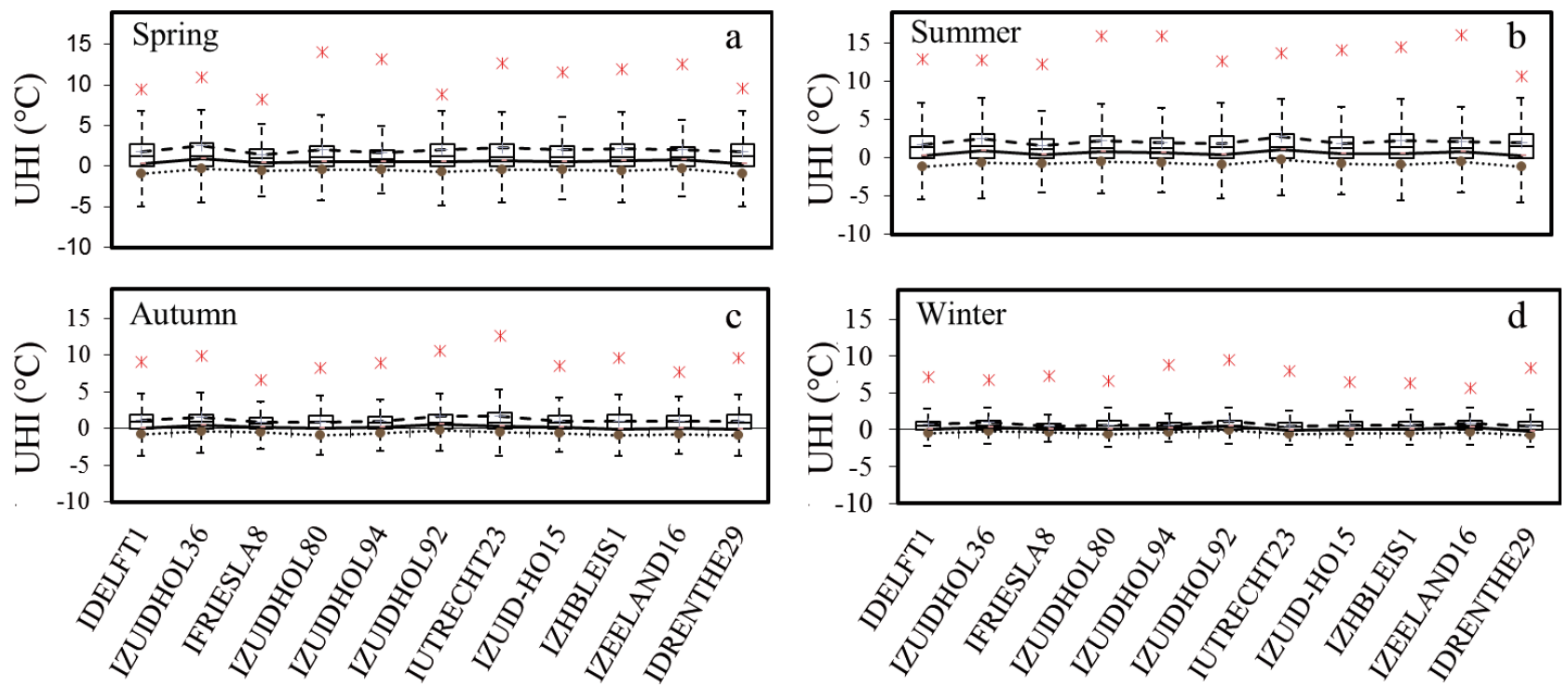

Fig. 4. Box-and-whisker plots for the personal amateur weather station (PWS) hourly urban heat island (UHI) from 2011 to 2015. Urban heat islands (UHIs) are plotted conditional on their occurrence during (a) spring, (b) summer, (c) autumn and (d) winter. Whiskers: 1.5 times the inter-quartile range; box lines: 0.25 (dotted), 0.5 (solid) and 0.75 (dashed) quantiles; red crossed dots: maximum data points for outliers

\subsection{UHI versus population density}

A quantitative relationship between UHI and cities has often been investigated by correlating the population and its UHI (Oke 1973). Further, the UHI intensity and magnitude are strongly dependent on the degree of urban development (e.g. urban sky visibility factors) at the investigated location (Van Hove et al. 2011). Population density has a stronger link to building topology and the characteristics of cities than does population number, and PD is further strongly linked to sky visibility factors (Giridharan et al. 2005). In this respect, The UHI intensity and its dependency on PD were investigated for the individual months of 2011-2015. A linear regression was obtained using least squares estimations comparing UHI (i.e. $\mathrm{UHI}_{\text {ave }}$ and $\mathrm{UHI}_{\max }$ ) and PD for the individual months. The relationships between UHI and PD for the daytime and diurnal cycles tend to have weak correlation coefficients (results not shown). In contrast, a significant positive relationship between UHI and PD was obtained for the night-time cycle. The coefficients of determination $\left(\mathrm{R}^{2}\right)$ for nightly $\mathrm{UHI}_{\text {ave }}$ and PD were estimated to be between 0.56 and 0.71 for the individual months (see Table 4).

The positive relationship between $\mathrm{UHI}_{\max }$ and PD can be observed for all months, despite the smaller $\mathrm{R}^{2}$ (between 0.29 and 0.67). The averaged slopes for $\mathrm{UHI}_{\text {ave }}$ and $\mathrm{UHI}_{\max }$ are $0.17^{\circ}$ and $0.43^{\circ} \mathrm{C}$, respectively, over all months. The regression line for $\mathrm{UHI}_{\text {ave }}$ has intercept values close to $0^{\circ} \mathrm{C}$, as expected for rural areas with population densities near 0. For $\mathrm{UHI}_{\max }$, the intercept values of the regression lines were larger (between $2.7^{\circ}$ and $5.5^{\circ} \mathrm{C}$ ) than those for $\mathrm{UHI}_{\text {ave. }}$. The greater intercept values for $\mathrm{UHI}_{\max }$ show that strong positive deviations of temperature could exist when $\mathrm{UHI}_{\text {ave }}$ is close to $0^{\circ} \mathrm{C}$.

Table 4. The linear relationship properties between the urban heat island $\left(\mathrm{UHI}_{i}{ }^{\circ} \mathrm{C}\right)$ and population density $\left(10^{3}\right.$ per $\left.\mathrm{km}^{2}\right)$ during the night-time cycle for the individual months between 2011 and 2015 . $\mathrm{R}^{2}$ : coefficient of determination; $\mathrm{a}, \mathrm{b}$ : slope and intercept values of the regression line

\begin{tabular}{|c|c|c|c|c|c|c|c|c|}
\hline \multirow[t]{2}{*}{ Index } & \multirow{2}{*}{$\mathrm{R}^{2}$} & \multicolumn{3}{|c|}{$-\mathrm{UHI}_{\mathrm{ave}} \mathrm{e}^{-}$} & \multirow[b]{2}{*}{$\mathrm{R}^{2}$} & \multicolumn{2}{|c|}{$-\mathrm{UHI}_{\max }-$} & \multirow[b]{2}{*}{$\mathrm{b}$} \\
\hline & & p-value & $\mathrm{a}$ & $\mathrm{b}$ & & p-value & $\mathrm{a}$ & \\
\hline Jan & 0.60 & 0.005 & 0.12 & 0.03 & 0.67 & 0.002 & 0.34 & 3.49 \\
\hline Feb & 0.57 & 0.007 & 0.10 & 0.23 & 0.45 & 0.025 & 0.75 & 3.17 \\
\hline Mar & 0.71 & 0.001 & 0.19 & 0.42 & 0.32 & 0.07 & 0.27 & 4.95 \\
\hline Apr & 0.69 & 0.002 & 0.22 & 0.66 & 0.32 & 0.068 & 0.31 & 5.5 \\
\hline May & 0.66 & 0.002 & 0.17 & 0.60 & 0.29 & 0.085 & 0.25 & 4.93 \\
\hline Jun & 0.71 & 0.001 & 0.20 & 0.67 & 0.55 & 0.009 & 0.80 & 3.79 \\
\hline Jul & 0.66 & 0.002 & 0.19 & 0.50 & 0.33 & 0.065 & 0.30 & 4.75 \\
\hline Aug & 0.56 & 0.008 & 0.18 & 0.39 & 0.30 & 0.08 & 0.23 & 4.9 \\
\hline Sep & 0.61 & 0.004 & 0.24 & 0.15 & 0.29 & 0.085 & 0.33 & 4.63 \\
\hline Oct & 0.70 & 0.001 & 0.18 & 0.02 & 0.47 & 0.02 & 0.39 & 4.6 \\
\hline Nov & 0.67 & 0.002 & 0.17 & -0.13 & 0.56 & 0.008 & 0.91 & 2.47 \\
\hline Dec & 0.57 & 0.008 & 0.10 & -0.09 & 0.49 & 0.016 & 0.26 & 3.12 \\
\hline
\end{tabular}




\subsection{Precipitation}

Fig. 5a shows that the total cumulative precipitation in urban areas increased more than that in rural areas between 2011 and 2015. The difference between the urban and rural cumulative precipitations from 2011 to 2015 was estimated to be nearly $65 \mathrm{~mm}$ (48-81 mm 95\% CI, p < 0.05).

Fig. $5 \mathrm{~b}$ shows the hourly precipitation in the cities was generally greater than that in the neighbouring rural areas. In the evening, the strengthened difference between urban and rural temperatures led to an increase in magnitude of UHI circulation with dynamically upward flow in urban areas, which could increase the possibility of precipitation occurrences in the evening and night-time. The decreased precipitation in the afternoon may indicate that the air convection in the afternoon is less marked with the smaller UHI. The average hourly precipitation amounts for the $5 \mathrm{yr}$ were approximately $0.11 \mathrm{~mm}$ $(0.09-0.12 \mathrm{~mm} 95 \% \mathrm{CI})$ in cities and $0.10 \mathrm{~mm}$ (0.09-0.11 mm $95 \% \mathrm{CI})$ in rural areas. The difference shows that the hourly precipitation that occurred was $7 \%$ greater in cities than in rural areas.

The average hourly precipitation in the summer was $0.14 \mathrm{~mm}(0.10-0.18 \mathrm{~mm} 95 \% \mathrm{CI})$ in cities and $0.13 \mathrm{~mm}(0.09-0.16 \mathrm{~mm} \mathrm{95 \%} \mathrm{CI)} \mathrm{in} \mathrm{rural} \mathrm{areas}$ (Fig. 5c). Additionally, the average hourly precipitation in the winter was $0.1 \mathrm{~mm}(0.07-0.12 \mathrm{~mm} 95 \% \mathrm{CI})$ in cities and $0.09 \mathrm{~mm}(0.06-0.11 \mathrm{~mm} 95 \% \mathrm{CI})$ in rural areas. Higher values of hourly precipitation and bigger differences between the city and rural precipita- tions occurred in the summer. These differences were more prominent during the night in the summer ( $0.15 \mathrm{~mm}$ in cities and $0.12 \mathrm{~mm}$ in rural areas).

Although the precipitation enhancement may be caused by many external influences, an overall enhancement of the precipitation could be expected based on the temperature increases. The urban extreme precipitation occurrences may have been expected to be more intense due to the warmer convective precipitation (Lenderink et al. 2011, Mishra et al. 2012).

The relationship between temperature and extreme precipitation (P90th) was further investigated by the WTF and PF. The estimated relationships between temperature and WTF or PF for each bin do not show a robust linear relationship (Fig. 6). However, the estimated relationships show that the regression slopes between the hourly temperatures and P90th values are more strongly influenced by PF variations than by WTF, suggesting that temperature has a greater impact on the intensity of extreme precipitation than on its frequency.

\subsection{Extreme value statistics}

The UHI, temperature and precipitation distributions were assessed by considering their diurnal maximum hourly occurrences for the individual months. The position of the probability distribution functions was characterized by the GEV distribution function for the hourly $\mathrm{UHI}_{\max }$ and the maximum hourly pre-
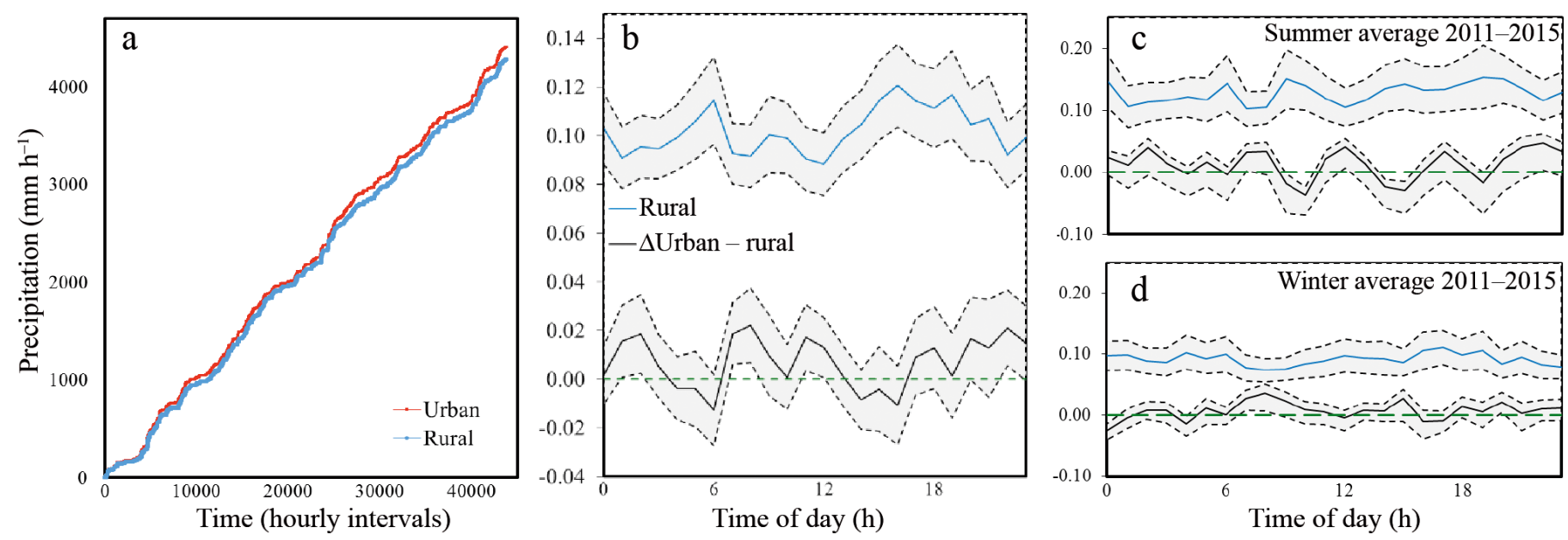

Fig. 5. (a) Time series plot of the hourly accumulated precipitation averaged for urban (red line) and rural stations (blue line). (b) Mean (solid line) and 95\% confidence intervals (shaded) of hourly precipitation between January 2011 and December 2015. Data are for rural stations (blue) and the difference in hourly precipitation between urban (PWS) and rural stations (AWS) (black). (c) Rural hourly precipitation (blue line) and differences in hourly precipitation between urban (PWS) and rural stations (AWS) (black line) between January 2011 and December 2015 for summer (upper panel) and winter (lower panel) 

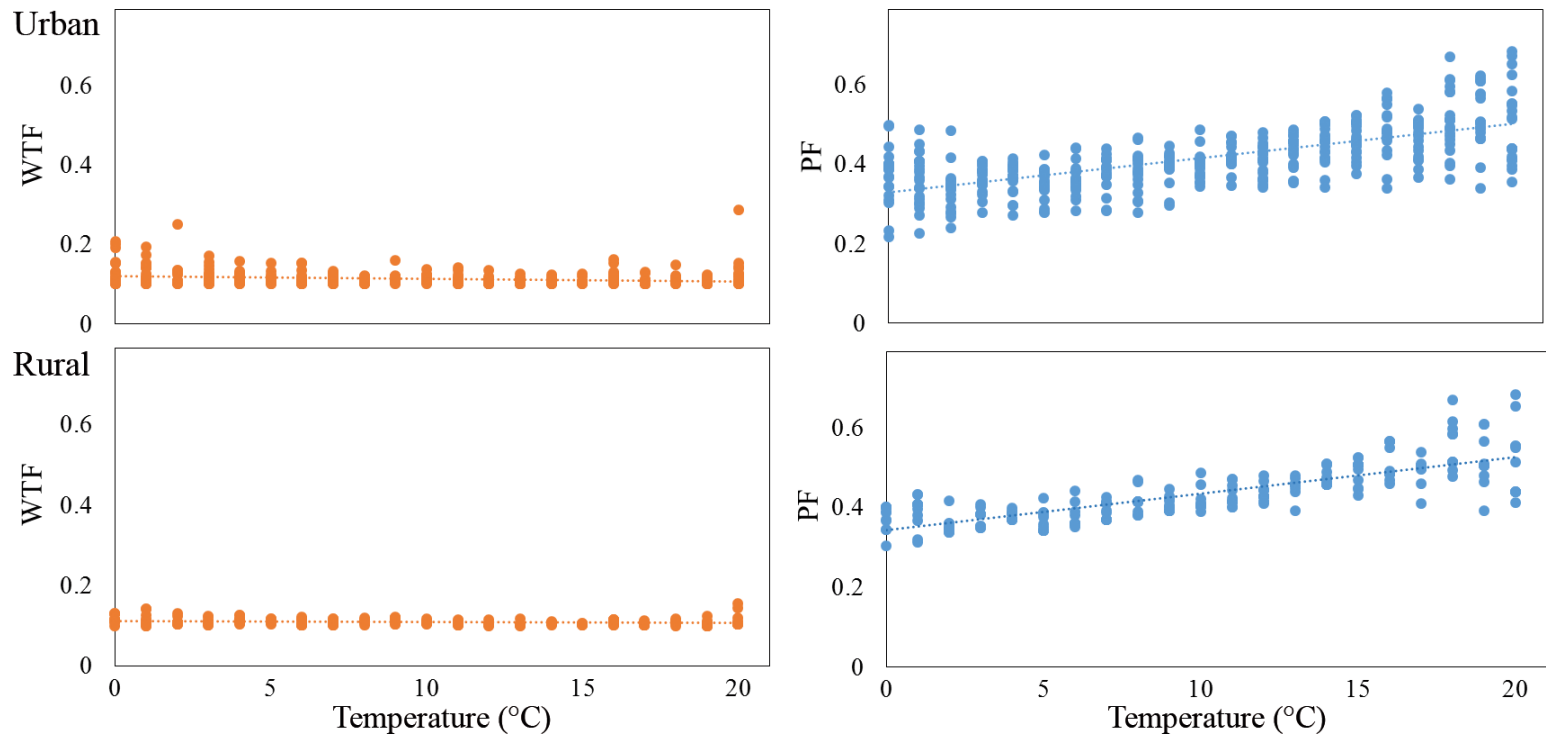

Fig. 6. Relationship between mean hourly temperature $\left({ }^{\circ} \mathrm{C}\right)$ in each bin and wet time fraction (WTF) as well as the precipitation fractional (PF) of extreme precipitation (>90th percentile) for urban (upper panels) and rural stations (bottom panels) at night-time during 2011-2015

cipitation. The estimated location parameters simply show the means of the distributions of the maximum hourly UHI and precipitation. Fig. 7a shows the UHI based on the investigated stations against the corresponding temperatures (e.g. both urban and rural) stratified by month. The UHI distribution was greater between March and September than during other months. The estimated location parameter of the maximum hourly precipitation over urban and rural stations was plotted against the estimated location parameter for the maximum hourly UHI for each month, as shown in Fig. 7b. The lowest values of the location parameter occurred in December and the highest values occurred in April and August.

These results suggest that the highest values of the maximum hourly precipitation and $\mathrm{UHI}_{\max }$ were evi-
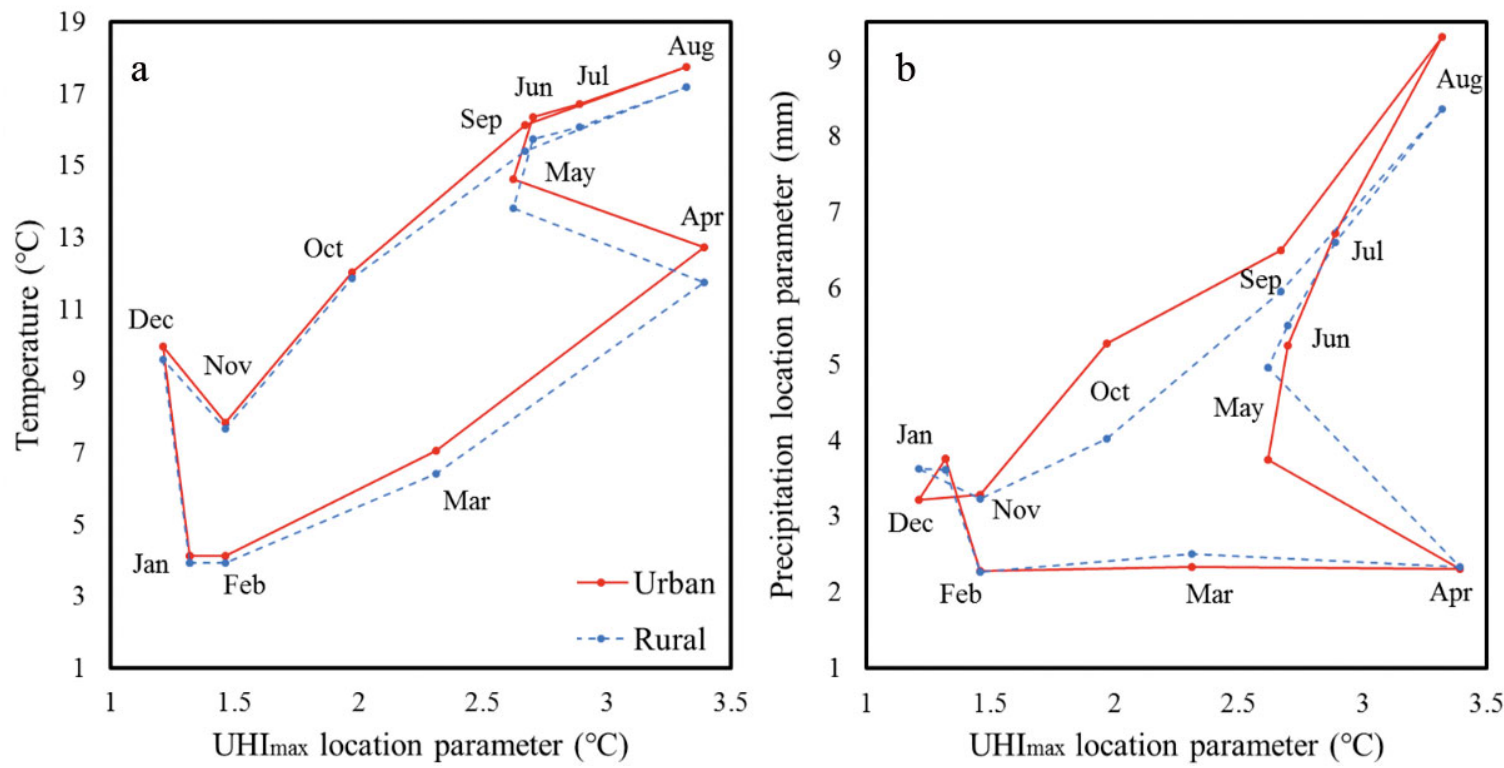

Fig. 7. (a) Estimated location parameters for the hourly maximum urban heat island (UHI $\mathrm{Uax}_{\text {ax }}$ against hourly temperature and (b) estimated location parameters for the maximum hourly precipitation. Data are averaged for urban (red solid line) and rural areas (blue dashed line) for the individual months 
dent in the summer months, and the difference between urban and rural precipitation tends to be greater in months with larger values for $\mathrm{UHI}_{\max }$ (Fig. 7b). In particular, the average maximum hourly precipitations in urban and rural areas were 9.30 and $8.36 \mathrm{~mm}$, respectively, in August. This difference reveals the maximum hourly precipitation in urban areas is approximately $11 \%$ larger than that in rural areas in August.

Fig. 7 shows a distinct seasonal cycle of the temperature and precipitation, which follows a closed loop and is based on urban-related warming. This cycle reveals the weakest and strongest urban-related warmings for the winter and summer, respectively. The maximum hourly UHI was depicted as having different amplitudes in the spring and autumn. The clockwise rotation of the UHI loop leads to the conclusion that urban areas warm up more quickly in the spring and cool off faster in the autumn. Stronger maximum hourly precipitation occurred in the summer and early autumn than in the other two seasons. Furthermore, the results show that more intense hourly extreme precipitation occurred in the autumn than in the spring. The seasonality of precipitation in The Netherlands, as indicated by previous studies (such as Rahimpour et al. 2016), shows that precipitation is enhanced in the summer and early autumn. Fig. 7 reveals that the urban precipitation in the late spring is more suppressed than the rural precipitation. Likewise, urban precipitation enhancement is larger than rural precipitation enhancement in the late summer and early autumn. Although there are different physical mechanisms behind the variation in precipitation, the results of the present study suggest that UHI effects influence precipitation in Dutch cities and that the urbanization-related difference has a distinct seasonal cycle, following a loop wherein the urbanization effect is strongest between August and October and weakest in the winter and spring.

\section{DISCUSSION}

Differences between urban and rural climates were investigated using amateur and automatic weather station networks. The PWS data of sufficiently high quality could provide long-term observations for the analysis of urban climates (Steeneveld et al. 2011). Unreliable data were excluded via QC of the PWS data (section 2.1). The measured variables of the selected PWS (Table 3) make it possible to detect the urban climate in more detail, not only in terms of air temperature but also in terms of other parameters.
Differences between temperature and precipitation in urban and rural areas were investigated. The UHI intensities reveal diurnal and seasonal inconsistencies, and could be influenced by mesoscale (Gedzelman et al. 2003) or synoptic weather conditions (Morris \& Simmonds 2000). The average monthly UHI indicates that urban areas were warmer than rural areas, except for some winter days. UHIs were found to be strongest in the late spring and summer and weakest in the winter. This could be attributed to seasonal influences on meteorological conditions. This distinct annual cycle is most likely caused by wind speed and insolation variations during the year (Wolters \& Brandsma 2012), since the winter in The Netherlands is known to have higher wind speeds, and the effects of surface properties (materials) on albedo and the surface energy budget differ in the winter and summer. A similar result was found by Arnds et al. (2017), with a radial gradient of about $2 \mathrm{~K}$ for Hamburg. They showed that a UHI radial gradient exhibits a seasonal cycle, with greater values between April and September and lower values in winter. The observed UHI annual cycle suggests that irradiation and vegetation period might be a relevant factor besides the weather condition frequency. UHI intensity enhancement in spring and summer also indicates that the vegetation period could induce greater differences in latent heat flux between urban and rural areas, even though Dutch cities are relatively green (Arnds et al. 2017).

The averaged UHI variations shown in Fig. 3 demonstrate that UHI intensity reaches a maximum in the evening $\left(2^{\circ} \mathrm{C}\right.$ at $\left.18: 00 \mathrm{~h} \mathrm{LT}\right)$. The results show that UHI and urban impacts may be similar for other European cities such as Poznan in central Europe, which was recently reported by Półrolniczak et al. (2017). The causes of UHI increases in the evening could be related to the much lower cooling rates of urban areas than those of rural areas after sunset. This difference is related to the high thermal capacity in urban areas and the low emissions of long-wave radiation back to the sky due to building densities (Unger 2004). Conversely, the UHI was minimized near sunrise, and this reduction continued into the morning. The negative values of UHI during the morning hours show that urban areas are cooler than their surrounding countryside. In other words, the mornings experienced the urban cool island (UCI) instead of the UHI. The maximum value of UCI averaged for all investigated cities was approximately $1.6^{\circ} \mathrm{C}$ at 08:00 $\mathrm{h}$ (LT). The UCI at all stations indicates that the investigated cities experienced shadow effects, which means that sunlight was prevented from reaching the cities in the morning 
(Oke 1982). The UCI of some winter days could be caused by the higher average wind speeds in winter, which result in stronger advection of rural air into cities (Wolters \& Brandsma 2012).

The UHI was found during the nights of all investigated urban areas. In addition to temperature and dew point, high sea level pressures with clear weather conditions in The Netherlands (Wolters \& Brandsma 2012) and greater humidity in rural areas than cities (which may be caused by the minimal evaporation [less vegetation] in cities during the day and higher temperatures at night) may lead to intensive UHI. Therefore, it can be deduced that the impacts of extreme UHI values can be diluted by combining the night and day datasets. This is in agreement with previous studies in The Netherlands (Steeneveld et al. 2011, Brandsma \& Wolters 2012, Klok et al. 2012, Van Hove et al. 2015).

The PD around each PWS station was linked to the monthly UHI between 2011 and 2015. The possible relationships between UHI and PD were significant only at night. The slopes of the regression lines for $\mathrm{UHI}_{\max }$ (extreme cases) are statistically significant and greater than those of $\mathrm{UHI}_{\mathrm{ave}}$ for all months. The medians of the linear slopes were obtained as 0.18 and $0.32^{\circ} \mathrm{C} 10^{3} \mathrm{~km}^{-2}$ for $\mathrm{UHI}_{\text {ave }}$ and $\mathrm{UHI}_{\max }$, respectively. Wolters \& Brandsma (2012) also linearized the relationship between UHI and PD for the nights between June 23 and July 24 2010. Their findings confirm our estimations; they found the medians of the relationship slopes to be 0.18 and $0.31^{\circ} \mathrm{C} 10^{3} \mathrm{~km}^{-2}$ for $\mathrm{UHI}_{\text {ave }}$ and $\mathrm{UHI}_{\max }$, respectively.

In addition to studying UHI, our study attempted to quantify the hourly precipitation discrepancies between cities and their surrounding areas. The overall features of the hourly precipitation analysis reveal greater values in cities than in the countryside, and the highest precipitation difference in the summer. The observed enhanced cumulative precipitation in urban areas is in agreement with the previous study on the urbanisation impacts on urban climates by Daniels et al. (2015), which showed a $7 \%$ enhancement of precipitation in Dutch cities. Thus, we confer further confidence to the recorded observations of the amateur stations.

The extreme precipitation sensitivity to temperature seems physically implausible due to other physical processes and factors (Lenderink \& Van Meijgaard 2010, Attema \& Lenderink 2014). However, the change from stratiform precipitation to more convective precipitation can be expected at higher temperatures (Lin et al. 2011). Precipitation enhancement (amount and intensity of short duration e.g. hourly) could be partially attributed to thermal effects from UHI in combination with stagnant weather systems resulting from other factors such as increases in the surface roughness and the strengthening air convection due to urbanization (Ren 2015). UHI (a low-level heat source) impacts on local flow (upward/downward motion) and circulations may lead to suppression or increase in convection or updrafts (Han \& Baik 2008). Further, the velocity perturbations in a stably stratified atmosphere could be decreased by the UHI-generated gravity waves (Han et al. 2014). Thus, water vapor transport and upward movement of convergence can be triggered by the UHI circulation, and the existence of enough moisture can lead to more precipitation in urban areas (Yang et al. 2017).

An enhanced precipitation difference was detected at night, in agreement with results from other urban areas (Ikebuchi et al. 2007, Yang et al. 2013, Dou et al. 2015); for example, Dixon \& Mote (2003) found that UHI enhancement increased night-time precipitation frequency in late spring and summer in Atlanta. Similar results reported by Chen et al. (2015) and Yang et al. (2017) showed that higher UHI intensity might induce stronger convection and cause larger hourly precipitation in urban areas than in the rural areas in the late evening and night-time. Furthermore, pronounced precipitation difference during the night-time hours could be related to the interaction between the weakening sea breeze and the UHI (Shepherd et al. 2010, Mitra et al. 2012). It is of note that the catch efficiency of precipitation could be influenced by the location of stations. The rural stations in open area are exposed to wind more than urban stations, which are surrounded by obstacles. The possibility of the larger catch efficiency of precipitation in urban stations than that in rural stations may result in uncertainty in the observed precipitation differences between urban and rural areas.

\section{CONCLUSIONS}

The influences of urbanization on the local climate were investigated by analyzing data from amateur meteorological stations in residential areas and automatic stations in the nearby countryside. The agreement between the results obtained in the present study and those of previous studies reflects the utility of amateur weather observations. The effects of urban areas on temperature (e.g. represented by UHI) and precipitation were analyzed over $5 \mathrm{yr}$. Despite the relatively small sizes of Dutch cities (with $<10 \mathrm{~km}$ radii), these cities do influence their climates. 
Dutch UHIs determined here are substantial and comparable to those of other European cities. The average UHI exceeded $2^{\circ} \mathrm{C}$ after sunset, indicating that UHI is a nocturnal phenomenon, while UCIs occur after sunrise in the morning. The cooling effect was found to be almost imperceptible at night.

The UHI intensities and their statistical distributions most likely depend on other weather parameters as well as the properties of the city and countryside. The links between the UHI and population densities (significant linear relationships at night were found in all months) show that higher UHI can occur in more densely populated urban areas. Additionally, the hourly extreme precipitation was strongest in the summer and more intense in the autumn than in the spring. This study quantified the precipitation enhancement over urban areas as being greater than that in nearby rural areas. The hourly precipitation in Dutch cities was estimated to be, on average, $7 \%$ greater than that in the countryside. The hourly temperature dependence of extreme precipitation shows that precipitation increases at a greater rate in cities than in rural areas.

Acknowledgements. This research was supported by the European Commission in the framework of Erasmus Mundus and the ITC PhD extension funding.

\section{LITERATURE CITED}

Allen MR, Ingram WJ (2002) Constraints on future changes in climate and the hydrologic cycle. Nature 419:224-232

Arnds D, Böhner J, Bechtel B (2017) Spatio-temporal variance and meteorological drivers of the urban heat island in a European city. Theor Appl Climatol 128:43-61

Attema JJ, Lenderink G (2014) The influence of the North Sea on coastal precipitation in the Netherlands in the present-day and future climate. Clim Dyn 42:505-519

Attema JJ, Loriaux JM, Lenderink G (2014) Extreme precipitation response to climate perturbations in an atmospheric mesoscale model. Environ Res Lett 9:014003

Barbero R, Fowler HJ, Lenderink G, Blenkinsop S (2017) Is the intensification of precipitation extremes with global warming better detected at hourly than daily resolutions? Geophys Res Lett 44:974-983

Berg P, Moseley C, Haerter JO (2013) Strong increase in convective precipitation in response to higher temperatures. Nat Geosci 6:181-185

Brandsma T, Konnen GP, Wessels HRA (2003) Empirical estimation of the effect of urban heat advection on the temperature series of De Bilt (The Netherlands). Int J Climatol 23:829-845

* Brandsma T, Wolters D (2012) Measurement and statistical modeling of the urban heat island of the city of Utrecht (Netherlands). J Appl Meteorol Climatol 51:1046-1060

Buishand TA, De Martino G, Spreeuw JN, Brandsma T (2013) Homogeneity of precipitation series in the Netherlands and their trends in the past century. Int J Climatol
33:815-833

CBS (Centraal Bureau voor de Statistiek) (2015) Toelichting Wijk- en Buurtkaart 2013, 2014 en 2015. https://www. cbs.nl/-/media/imported/documents/2016/53/2015ep33toelichting-wijk-en-buurtkaart-2013-2015.pdf

Chen S, Li WB, Du YD, Mao CY, Zhang L (2015) Urbanization effect on precipitation over the Pearl River Delta based on CMORPH data. Adv Clim Chang Res 6:16-22

Coles S (2001) An introduction to statistical modeling of extreme values. Springer Verlag, London

Daniels EE, Lenderink G, Hutjes RWA, Holtslag AAM (2015) Short Communication Observed urban effects on precipitation along the Dutch West coast. Int J Climatol 2119: 2111-2119

Data C (2009) Guidelines on analysis of extremes in a changing climate in support of informed decisions for adaptation. WMO-TD No. 1500. World Meteorological Organization, Geneva

Dixon PG, Mote TL (2003) Patterns and causes of Atlanta's urban heat island-initiated precipitation. J Appl Meteorol 42:1273-1284

* Dou J, Wang Y, Bornstein R, Miao S (2015) Observed spatial characteristics of Beijing urban climate impacts on summer thunderstorms. J Appl Meteorol Climatol 54:94-105

EEA (European Environmental Agency) (2017) Landscapes in Transition. An account of 25 years of land cover change in Europe. EEA Report 10/2017, EEA, Copenhagen

Erell E, Pearlmutter D, Williamson T (2011) Urban microclimate: designing the spaces between buildings. Earthscan, London

* Gedzelman SD, Austin S, Cermak R, Stefano N, Partridge S, Quesenberry S, Robinson DA (2003) Mesoscale aspects of the Urban Heat Island around New York City. Theor Appl Climatol 75:29-42

Giridharan R, Lau SSY, Ganesan S (2005) Nocturnal heat island effect in urban residential developments of Hong Kong. Energy Build 37:964-971

*Haines A, Kovats RS, Campbell-Lendrum D, Corvalan C (2006) Climate change and human health: Impacts, vulnerability and public health. Public Health 120:585-596

*Hamdi R, Schayes G (2008) Sensitivity study of the urban heat island intensity to urban characteristics. Int J Climatol 28:973-982

*Han JY, Baik JJ (2008) A theoretical and numerical study of urban heat island-induced circulation and convection. J Atmos Sci 65:1859-1877

*Han JY, Baik JJ, Lee H (2014) Urban impacts on precipitation. Asia-Pacific J Atmos Sci 50:17-30

*Hazeu GW, Bregt AK, de Wit AJW, Clevers JGPW (2011) A Dutch multi-date land use database: identification of real and methodological changes. Int J Appl Earth Obs Geoinf 13:682-689

* Hu Z, Yu B, Chen Z, Li T, Liu M (2012) Numerical investigation on the urban heat island in an entire city with an urban porous media model. Atmos Environ 47:509-518

Ikebuchi S, Tanaka K, Ito Y, Moteki Q (2007) Investigation of the effects of urban heating on the heavy rainfall event by a cloud resolving model CReSiBUC. Annu Disaster Prev Res Inst Kyoto Univ 50:105-111

Jarraud M (2008) Guide to meteorological instruments and methods of observation (WMO-No. 8), World Meteorological Organisation. Geneva

Jenkinson AF (1955) The frequency distribution of the annual maximum (or minimum) values of meteorological 
elements. R Meteorol Soc 81:158-171

Jiang Q, Kresin F, Bregt AK, Kooistra L and others (2016) Citizen sensing for improved urban environmental monitoring. J Sens 2016:5656245

Kaufmann RK, Seto KC, Schneider A, Liu Z, Zhou L, Wang W (2007) Climate response to rapid urban growth: evidence of a human-induced precipitation deficit. J Clim 20:2299-2306

Klein Tank AMG (2007) EUMETNET/ECSN optional programme: European Climate Assessment \& Dataset (ECA\&D) Algorithm Theoretical Basis Document (ATBD), version 4. Royal Netherlands Meteorological Institute (KNMI), De Bilt

Klok L, Zwart S, Verhagen H, Mauri E (2012) The surface heat island of Rotterdam and its relationship with urban surface characteristics. Resour Conserv Recycling 64: 23-29

Lenderink G, van Meijgaard E (2008) Increase in hourly precipitation extremes beyond expectations from temperature changes. Nat Geosci 1:511-514

Lenderink G, Van Meijgaard E (2010) Linking increases in hourly precipitation extremes to atmospheric temperature and moisture changes. Environ Res Lett 5:025208

Lenderink G, Mok HY, Lee TC, Van Oldenborgh GJ (2011) Scaling and trends of hourly precipitation extremes in two different climate zones-Hong Kong and the Netherlands. Hydrol Earth Syst Sci 15:3033-3041

Lin CY, Chen WC, Chang PL, Sheng YF (2011) Impact of the Urban Heat Island effect on precipitation over a complex geographic environment in northern Taiwan. J Appl Meteorol Climatol 50:339-353

McLaren C, Null J, Quinn J (2005) Heat stress from enclosed vehicles: moderate ambient temperatures cause significant temperature rise in enclosed vehicles Pediatrics 116: e109-e112

Mills G (2014) Urban climatology: history, status and prospects. J Urban Clim 10:479-489

Mishra V, Wallace JM, Lettenmaier DP (2012) Relationship between hourly extreme precipitation and local air temperature in the United States. Geophys Res Lett 39:1-7

Mitra C, Shepherd JM, Jordan T (2012) On the relationship between the premonsoonal rainfall climatology and urban land cover dynamics in Kolkata city, India. Int J Climatol 32:1443-1454

Morris CJG, Simmonds I (2000) Associations between varying magnitudes of the urban heat island and the synoptic climatology in Melbourne, Australia. Int J Climatol 20: 1931-1954

Niyogi D, Pyle P, Lei M, Arya SP and others (2011) Urban modification of thunderstorms: an observational storm climatology and model case study for the Indianapolis urban region. J Appl Meteorol Climatol 50:1129-1144

Oke TR (1973) City size and the urban heat island. Atmos Environ 7:769-779

Oke TR (1982) The energetic basis of the urban heat island. QJR Meteorol Soc 108:1-24

Oke TR (2004) Initial guidance to obtain representative meteorological observations at urban sites. WMO/TDNo. 1250. World Meteorological Organization, Geneva

Overeem A, Holleman I, Buishand A (2008) Extreme rainfall climatology from weather radar. http://projects.knmi.nl/ publications/fulltexts/triennial_2010_overeem.pdf

Pall P, Allen MR, Stone Da (2007) Testing the ClausiusClapeyron constraint on changes in extreme precipitation under $\mathrm{CO}_{2}$ warming. Clim Dyn 28:351-363
Panthou G, Mailhot A, Laurence E, Talbot G (2014) Relationship between surface temperature and extreme rainfalls: a multi-timescale and event-based analysis. J Hydrometeorol 15:1999-2011

* Pattengale ND, Alipour M, Bininda-Emonds OR, Moret BM, Stamatakis A (2009) How many bootstrap replicates are necessary? J Comput Biol 17:337-354

Peterson TC (2003) Assessment of urban versus rural in situ surface temperatures in the contiguous United States: no difference found. J Clim 16:2941-2959

Półrolniczak M, Kolendowicz L, Majkowska A, Czernecki B (2017) The influence of atmospheric circulation on the intensity of urban heat island and urban cold island in Poznań, Poland. Theor Appl Climatol 127:611-625

* Rahimpour Golroudbary V, Zeng Y, Mannaerts CM, Su Z (2016) Attributing seasonal variation of daily extreme precipitation events across The Netherlands. Weather Clim Extrem 14:56-66

Rahimpour Golroudbary V, Zeng Y, Mannaerts CM, Su Z (2017) Detecting the effect of urban land use on extreme precipitation in the Netherlands. Weather Clim Extrem $17: 36-46$

Ren GY (2015) Urbanization as a major driver of urban climate change. Adv Clim Chang Res 6:1-6

Rovers V, Bosch P, Albers R, Spit T (2014) Climate proof cities. TNO. KfC Report no. 129/2004. https://dspace. library.uu.nl/bitstream/handle/1874/314903/CPC_final_ report_eng.pdf? sequence $=1$

Ryu YH, Baik JJ (2012) Quantitative analysis of factors contributing to urban heat island intensity. J Appl Meteorol Climatol 51:842-854

Sailor DJ (2011) A review of methods for estimating anthropogenic heat and moisture emissions in the urban environment. Int J Climatol 31:189-199

* Schlünzen $\mathrm{KH}$, Hoffmann $\mathrm{P}$, Rosenhagen $\mathrm{G}$, Riecke W (2010) Long-term changes and regional differences in temperature and precipitation in the metropolitan area of Hamburg. Int J Climatol 30:1121-1136

* Shem W, Shepherd M (2009) On the impact of urbanization on summertime thunderstorms in Atlanta: two numerical model case studies. Atmos Res 92:172-189

Shepherd JM (2005) A review of current investigations of urban-induced rainfall and recommendations for the future. Earth Interact 9:1-27

* Shepherd JM, Carter M, Manyin M, Messen D, Burian S (2010) The impact of urbanization on current and future coastal precipitation: a case study for Houston. Environ Plann B Plann Des 37:284-304

Steeneveld GJ, Koopmans S, van Hove LWA, Holtslag AAM (2010) Urban heat island effects and human comfort in a mild $\mathrm{Cfb}$ climate: exploring long term observations by hobby meteorologists in The Netherlands. In: 9th Symposium on the Urban Environment, American Meteorological Society, 2-6 August 2010, Keystone, CO, USA, Paper 1.3

Steeneveld GJ, Koopmans S, Heusinkveld BG, Van Hove LWA, Holtslag AAM (2011) Quantifying urban heat island effects and human comfort for cities of variable size and urban morphology in the Netherlands. J Geophys Res Atmos 116:1-14

* Stewart ID, Oke TR (2012) Local climate zones for urban temperature studies. Bull Am Meteorol Soc 93:1879-1900

Stone B, Vargo J, Habeeb D (2012) Managing climate change in cities: will climate action plans work? Landsc Urban Plan 107:263-271 
Suomi J, Hjort J, Käyhkö J (2012) Effects of scale on modelling the urban heat island in Turku, SW Finland. Clim Res 55:105-118

* Trusilova K, Jung M, Churkina G, Karsten U, Heimann M, Claussen M (2008) Urbanization impacts on the climate in Europe: numerical experiments by the PSU-NCAR mesoscale model (MM5). J Appl Meteorol Climatol 47: 1442-1455

Un D (2015) World urbanization prospects: the 2014 revision. ST/ESA/SER. A/366, United Nations Department of Economic and Social Affairs, Population Division. https:// esa.un.org/unpd/wup/publications/files/wup2014-report. pdf

* Unger J (2004) Intra-urban relationship between surface geometry and urban heat island: review and new approach. Clim Res 27:253-264

Van Hove LWA, Steeneveld GJ, Jacobs CMJ, Heusinkveld BG, Elbers JA, Moors EJ, Holtslag AAM (2011) Exploring the urban heat island intensity of Dutch cities: assessment based on a literature review, recent meteorological observations and datasets provided by hobby meteorologists. Report 2170, Alterra, Wageningen

Van Hove LWA, Jacobs CMJ, Heusinkveld BG, Elbers JA, van Driel BL, Holtslag AAM (2015) Temporal and spatial variability of urban heat island and thermal comfort within the Rotterdam agglomeration. Build Environ 83:91-103

Wiacek A, Taylor JR, Strong K, Saari R, Kerzenmacher TE,

Editorial responsibility: Guoyu Ren, Beijing, China
Jones NB, Griffith DWT (2007) Ground-based solar absorption FTIR spectroscopy: characterization of retrievals and first results from a novel optical design instrument at a new NDACC complementary station. J Atmos Ocean Technol 24:432-448

*Willems P, Arnbjerg-Nielsen K, Olsson J, Nguyen VTV (2012) Climate change impact assessment on urban rainfall extremes and urban drainage: methods and shortcomings. Atmos Res 103:106-118

WMO (World Meteorological Organization) (2007) Guide to the Global Observing System. Report No. 488. WMO-No. 488 170. WMO, Geneva

*Wolters D, Brandsma T (2012) Estimating the urban heat island in residential areas in the Netherlands using observations by weather amateurs. J Appl Meteorol Climatol 51:711-721

* Yang P, Ren G, Hou W, Liu W (2013) Spatial and diurnal characteristics of summer rainfall over Beijing Municipality based on a high-density AWS dataset. Int J Climatol 33:2769-2780

* Yang P, Ren G, Yan P (2017) Evidence for a strong association of short-duration intense rainfall with urbanization in the Beijing urban area. J Clim 30:5851-5870

* Zhang CL, Chen F, Miao SG, Li QC, Xia XA, Xuan CY (2009) Impacts of urban expansion and future green planting on summer precipitation in the Beijing metropolitan area. J Geophys Res 114:D02116

Submitted: October 23, 2017; Accepted: February 13, 2018

Proofs received from author(s): May 13, 2018 